JOSÉ MARIA SOARES JÚNIOR ${ }^{1}$

Felisbela SoARes de Holanda ${ }^{2}$

EDMUND ChADA BARACAT ${ }^{3}$

\section{Melatonina e puberdade: quais as evidências?}

\author{
Melatonin and puberty: what is the evidence?
}

Correspondência:

José Maria Soares Júnio Departamento de Ginecologia da Universidade Federal de São Paulo Rua Borges Lagoa, $715,7^{\circ}$ andar - Vila Clementino CEP 04023-900 - São Paulo/SP E-mail: jsoares415@hotmail.com
Os estudos da função da pineal tiveram grande impulso após a síntese da melatonina por Lerner et al. ${ }^{1}$. O termo "melatonina" advém da propriedade que este hormônio apresenta de clarear a pele de girinos, agregando grânulos de melanina presentes nos melanócitos desses anfíbios ${ }^{1}$.

A melatonina, conhecida farmacologicamente como 5-metoxi-N-acetil-triptamina, é o principal hormônio da pineal. Sua síntese é regulada por neurotransmissores, que partem do terminal pós-ganglionar simpático e pelo núcleo supraquiasmático, como a norepinefrina, e que facilitam a entrada do triptofano no interior dos pinealócitos. Em seguida, este é hidroxilado em 5-hidroxitriptofano, o qual, por ação da enzima L-aminoácido aromático descarboxilase, se converte em serotonina (5-hidroxitriptamina). O aumento do AMP cíclico leva à atividade da $\mathrm{N}$-acetiltransferase, etapa limitadora da velocidade na síntese de melatonina, que converte a serotonina em $\mathrm{N}$-acetilserotonina ( $\mathrm{N}$-acetil-T-hidroxitriptamina). Esta é então transformada em melatonina por ação da HIOMT (hidroxi-indol-O-metiltransferase). Por fim, este hormônio atinge a corrente sangüínea, por difusão passiva dos pinealócitos para as veias portas da pineal. É importante lembrar que a melatonina é metabolizada em dois compostos: 6-hidroximelatonina e 6-sulfatoximelatonina. Este último metabólito é o melhor indicador da produção de melatonina ${ }^{2}$.

A melatonina e o seu principal metabólito, a 6-sulfatoximelatonina, podem ser medidos por radioimunoensaio (RIA) ou Enzyme-Linked Immuno Sorbent Assay (ELISA). Plasma, soro ou saliva podem ser usados para aquilatar a melatonina, e a urina, para os seus metabólitos. O horário da coleta é crucial, visto que o seu pico é noturno. Os níveis de melatonina são essenciais para a regulação do relógio biológico em cada indivíduo ${ }^{2}$.

Saliente-se, ainda, que os níveis de triptofano e de serotonina aumentam durante o período diurno, ao contrário dos da melatonina, que se elevam na ausência de luz (noturno), atingindo valores de 40 a 400 pM, com ápice ao redor da meia-noite ${ }^{2}$. Posteriormente, há queda durante o dia, quando se detectam os menores níveis sangüíneos².

A pineal é amplamente aceita como a glândula reguladora da reprodução em mamíferos, pela capacidade de influenciar a função gonadal e promover a ciclicidade estral ${ }^{3}$. Sua atividade, na rata, com freqüência, é avaliada pelos níveis de melatonina, os quais variam de acordo com as diferentes fases do ciclo estral ${ }^{2}$.

Os efeitos da melatonina na função gonadal dependem da espécie de animal estudado. Assim, na ovelha e no hamster, a melatonina teria ação pró-gonadotrófica; já no ser humano,

Coordenador do Setor de Ginecologia da Infância e da Adolescência do Departamento de Ginecologia da Universidade Federal de São Paulo - UNIFESP - São Paulo (SP), Brasil.

${ }_{2}$ Mestre do Setor de Ginecologia da Infância e da Adolescência do Departamento de Ginecologia da Universidade Federal de São Paulo - UNIFESP - São Paulo (SP), Brasil.

3 Professor Titular da Disciplina de Ginecologia do Departamento de Obstetrícia e Ginecologia da Faculdade de Medicina da Universidade de São Paulo - USP - São Paulo (SP), Brasil. 
em primatas e em alguns roedores, como o camundongo e o rato, ela apresenta ação antigonadotrófica. Sua ação no sistema reprodutor é mediada por receptores no hipotálamo que podem alterar a secreção dos pulsos do hormônio liberador das gonadotrofinas $(\mathrm{GnRH})$, que, por sua vez, controla a secreção das gonadotrofinas (hormônio folículoestimulante (FSH) e hormônio luteinizante (LH)), pela hipófise $e^{3}$.

A freqüência de liberação do GnRH é de, aproximadamente, um pulso a cada 90 minutos na fase folicular, e a cada 220 minutos, na fase lútea. Entre suas funções, ressalta-se o controle sobre a hipófise anterior, modulando a síntese e a liberação de LH e FSH, que são essenciais à função gonadal. Sua liberação pode ser modificada pela melatonina, principalmente durante o final da fase lútea e o início do período menstrual, com diminuição da freqüência dos pulsos, o que também repercute na hipófise e nas gônadas ${ }^{4}$.

Outro local de ação da melatonina seria a adenohipófise, nas células que produzem prolactina (PRL). Enquanto as ações biológicas do FSH e do LH concentram-se no sistema genital, a PRL age nos processos metabólitos e no balanço hídrico. Assim, a melatonina também poderia atuar no balanço hidroeletrolítico 5 . Experimentalmente, foi comprovada a existência de receptores de melatonina na pars tuberalis da hipófise em alguns mamíferos, bem como a sua ação sobre a liberação de $\mathrm{PRL}^{4}$.

Como se sabe, a PRL interfere com os níveis de gonadotrofinas. Assim, quanto maior sua concentração, menor serão os valores de FSH e de LH. Ademais, a PRL é importante para a degradação do corpo lúteo e para a redução dos níveis dos esteróides sexuais no ciclo menstrual. Há estudos que mostram que os maiores valores de PRL são detectados durante o período noturno e que a melatonina poderia modular sua liberação ${ }^{4}$.

Recentemente, surgiram evidências da ação direta da melatonina no ovário de ratas, após a identificação dos receptores de melatonina $\mathrm{MT}_{1}$ e $\mathrm{MT}_{2}$ neste órgão ${ }^{6}$, inclusive em mulheres ${ }^{7}$. Além disso, há dados que indicam que os níveis de melatonina flutuam durante o ciclo menstrual, sendo mais baixos durante a ovulação, elevando-se nos dias subseqüentes, atingindo níveis mais altos durante a menstruação. Outro fato relevante é a presença de concentrações muito elevadas de melatonina no fluido folicular ovariano, sendo três vezes superiores aos da corrente sangüínea ${ }^{8}$. Há, ainda, relato da interação do receptor de melatonina com os esteróides sexuais ovarianos, principalmente o estrogênio?.

Pacientes com anovulação crônica e hiperandrogenismo (síndrome dos ovários policísticos) teriam valores de 6-sulfatoximelatonina significantemente superiores aos de mulheres normais ou das com hirsutismo idiopático ${ }^{10}$. Este achado sugere que a melatonina atuaria na regulação do sistema reprodutor, possivelmente no eixo hipotálamohipofisário-ovariano (EHHO). Outra possibilidade seria que o distúrbio hormonal das pacientes com síndrome dos ovários polcísticos pudesse interferir na produção de melatonina pela pineal, visto que há receptores de estrogênio e de progesterona nesta glândula.

Embora os seres humanos não sejam animais sazonais, podem ocorrer variações ocasionais na resposta reprodutiva durante as estações do ano, nas quais a produção de melatonina estaria também envolvida ${ }^{2}$. Demonstrou-se que enxertos de melatonina provocam função inibitória no hipotálamo e retardo na maturação sexual em hamsters. Já a redução dos níveis de melatonina abaixo de um valor limiar $(100 \mathrm{pg} / \mathrm{mL})$ poderia se constituir em um sinal de ativação da secreção hipotalâmica pulsátil de GnRH e, conseqüentemente, iniciar o desenvolvimento sexual ${ }^{11}$.

Durante o desenvolvimento da criança, os níveis séricos de melatonina atingem os maiores valores na fase prépubere, para, em seguida, diminuírem progressivamente até o final da puberdade. Após este período, seus níveis sofrem variações cíclicas na mulher até a perimenopausa, quando ocorre pequena elevação e, posteriormente, nova queda até a senectude ${ }^{12,13}$.

O efeito da melatonina no amadurecimento sexual apresenta um processo biológico de transição do estado sexual imaturo para o maduro. Tal fato se deve à reativação do EHHO, que se acha bloqueado durante a infância ${ }^{4}$. Há controvérsias sobre o determinismo da puberdade, sobretudo em relação ao sinal a partir do qual se iniciaria o desenvolvimento puberal. Sabe-se que a melatonina influenciaria a maturação do eixo hipotálamo-hipofisário. Assim, a produção elevada deste hormônio, típica do período pré-puberal, manteria o hipotálamo em estado de quiescência ${ }^{11,14}$, exercendo efeito modulador sobre as gonadotrofinas. Outro mecanismo sugere que a melatonina reduziria a resposta hipofisária ao GnRH. No período puberal, ocorreria queda da produção de melatonina. A glândula pineal permitiria a ativação do gerador hipotalâmico de pulsos de GnRH e, conseqüentemente, do eixo reprodutor, com início dos fenômenos endócrinos puberais ${ }^{11,14}$.

Reforçando a relação entre o desenvolvimento puberal e a produção de melatonina, alguns autores acreditam que, durante a infância, haveria refratariedade da resposta hipotalâmica aos esteróides circulantes, por ação direta de indóis, como a serotonina e a melatonina. Esta refratariedade decresceria com o evolver dos anos, e a maior sensibilidade aos esteróides circulantes daria início aos fenômenos puberais, com influência recíproca do sistema nervoso central e das gônadas. Gupta et al. ${ }^{15}$ verificaram que os níveis de melatonina declinam progressivamente, e de modo significativo, 
na mesma proporção em que se processa o amadurecimento sexual e com o aparecimento da puberdade. A melatonina seria, pois, o hormônio antigonadotrópico que inibiria o amadurecimento sexual precoce ${ }^{16}$. A redução progressiva dos seus níveis circulantes facultaria a ação das gonadotrofinas e o surgimento dos fenômenos puberais. Em nosso meio, verificamos que há queda acentuada dos níveis da melatonina em meninas com puberdade normal, bem como naquelas com puberdade precoce, em relação às meninas na mesma faixa etária sem sinais de desenvolvimento puberal. Portanto, a melatonina poderia influenciar no início da puberdade.

\section{Referências}

1. Lerner AB, Case JD, Takahashi Y, Lee TH, Mori W. Isolation of melatonin, the pineal gland factor that lightens melanocytes. J Am Chem Soc. 1958;80(10):2587.

2. Maganhin CC, Carbonel AAF, Hatty JH, Fuchs LFP, Oliveira-Júnior IS, Simões $\mathrm{W}$, et al. Efeitos da melatonina no sistema genital feminino: breve revisão. Rev Assoc Med Bras. 2008;54(3):267-71.

3. Dair EL, Simoes RS, Simões M, Romeu LR, Oliveira-Filho RM, Haidar MA, et al. Effects of melatonin on the endometrial morphology and embryo implantation in rats. Fertil Steril. 2008;89(5 Suppl): 1299-305.

4. Díaz López B, Díaz Rodríguez E, Urquijo C, Fernández Alvarez C. Melatonin influences on the neuroendocrine-reproductive axis. Ann N Y Acad Sci. 2005; 1057:337-64.

5. Soares Junior JM, Baracat EC, Oliveira S, Haidar MA, Simöes M, Reis LC. Influência da glândula pineal sobre a ingestão de água e NaCL em ratas normais e ooforectomizadas. Rev Bras Ginecol Obstet. 1999;21(6):317-21.

6. Soares JM Jr, Masana MI, Er ahin C, Dubocovich ML. Functional melatonin receptors in rat ovaries at various stages of the estrous cycle. J Pharmacol Exp Ther. 2003;306(2):694-702.

7. Woo MM, Tai CJ, Kang SK, Nathwani PS, Pang SF, Leung PC. Direct action of melatonin in human granulosa-luteal cells. J Clin Endocrinol Metab. 2001;86(10):4789-97.

8. Rönnberg L, Kauppila A, Leppäluoto J, Martikainen H, Vakkuri O. Circadian and seasonal variation in human preovulatory follicular fluid melatonin concentration. J Clin Endocrinol Metab. 1990;71(2):492-6.

9. Masana MI, Soares JM Jr, Dubocovich ML. 17Beta-estradiol modulates hMT1 melatonin receptor function. Neuroendocrinology. 2005;81 (2):87-95

10. Luboshitzky R, Qupti G, Ishay A, Shen-Orr Z, Futerman B, Linn S. Increased 6-sulfatoxymelatonin excretion in women with polycystic ovary syndrome. Fertil Steril. $2001 ; 76(3): 506-10$.

11. Molina-Carballo A, Fernández-Tardáguila E, Uberos-Fernández J, Seiquer I, Contreras-Chova F, Muñoz-Hoyos A. Longitudinal study of the simultaneous secretion of melatonin and leptin during normal puberty. Horm Res. 2007;68(1):11-9.

12. Messinis IE. From menarche to regular menstruation: endocrinological background. Ann N Y Acad Sci. 2006;1092:49-56.

13. Okatani Y, Morioka N, Wakatsuki A. Changes in nocturnal melatonin secretion in perimenopausal women: correlation with endogenous estrogen concentrations. J Pineal Res. 2000;28(2):111-8.

14. Aleandri V, Spina V, Ciardo A. II ruolo delia pineale nel controllo endocrino della pubertà. Min Ginecol. 1997;49(1-2):43-8.

15. Gupta D, Riedel L, Frick HJ, Attanasio A, Ranke MB. Circulating melatonin in children: in relation to puberty, endocrine disorders, functional tests and racial origin. Neuro Endocrinol Lett. 1983;5(2):63-78.

16. Brzezinski A, Wurtman RJ. The pineal gland: its possible roles in human reproduction. Obstet Gynecol Surv. 1988;43(4):197-207. 